\title{
ENTREVISTA COM JULIO CÉSAR SANTOYO
}

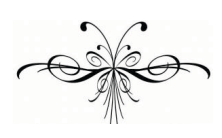

Julio CÉSAR SANTOYo / ANNA GIL BARDAJI ${ }^{1}$

JULIO CÉSAR SANTOYO es catedrático de Filología Inglesa y de Traducción e Interpretación en la Universidad de León. Autor de más de 130 artículos y capítulos de libros sobre teoría, historia y bibliografía de la traducción, literatura inglesa e historia de la imprenta, es también traductor de obras de J. R. R. Tolkien, R. L. Stevenson, Oscar Wilde, E. A. Poe, Christopher Marlowe, Rudyard Kipling, Washington Irving, entre otros, y autor de numerosos libros, entre los que destacan Ediciones y traducciones inglesas del Lazarillo de Tormes, 1568-1977 (1978), La cultura traducida (1983), El delito de traducir (1985), De clásicos y traducciones (1987), Teoría y crítica de la traducción: Antología (1987), Bibliografía española de la traducción (1996), Las páginas olvidadas: Reflexiones sobre canon, literatura y traducción (1998), Historia de la traducción: Quince apuntes (1999), e Historia de la traducción: viejos y nuevos
Julio CÉsar SAntoyo é catedrático de Letras Inglês e de Tradução e Interpretação na Universidad de León. Autor de mais de 130 artigos e capítulos de livros sobre teoria, história e bibliografia da tradução, literatura inglesa e história da imprensa, é também tradutor de obras de J. R. R. Tolkien, R. L. Stevenson, Oscar Wilde, E. A. Poe, Christopher Marlowe, Rudyard Kipling, Washington Irving, entre outros, e autor de numerosos livros, dentre os quais se destacam Ediciones y traducciones inglesas del Lazarillo de Tormes, 1568-1977 (1978), La cultura traducida (1983), El delito de traducir (1985), De clásicos y traducciones (1987), Teoría y crítica de la traducción: Antología (1987), Bibliografía española de la traducción (1996), Las páginas olvidadas: Reflexiones sobre canon, literatura y traducción (1998), Historia de la traducción: Quince apuntes (1999), e Historia de la traducción: viejos y nuevos

\footnotetext{
${ }^{1}$ Os editores de Scientia Traductionis agradecem a Montserrat Bacardí e Ramon Farrés, coordenadores de Quaderns: Revista de Traducció, e a Anna Gil Bardají, pela gentil permissão para reproduzir a presente entrevista, publicada originalmente em Quaderns: Revista de Traducció, 17, 2010, pp. 271-281. (ISSN 1138-5790).
} 
apuntes (2008). Su último título, La traducción medieval en la península ibérica, siglos III-XV, publicado en 2009, es el fruto de numerosos años de trabajo y la culminación de toda una trayectoria investigadora en torno a la historia de la traducción en el Medievo peninsular.

Anna Gil: En primer lugar, muchas gracias por haber escrito esta apasionante historia de la traducción medieval en la península ibérica. Con su publicación, me parece que no sólo se colma un enorme vacío investigador, sino que se convierte en una obra de referencia ineludible para los estudios medievales, en general, $y$ en los estudios de traducción, en particular. De nuevo, muchísimas gracias y enhorabuena por su excelente trabajo.

Empecemos por el final. Usted concluye su libro planteando la siguiente pregunta: ¿Hasta cuándo la historia de la traducción va a seguir ausente, como lo ha estado hasta ahora, de las respectivas historias de la literatura, de la ciencia, de la religión, de la cultura medieval peninsular en general, y de la catalana, castellana, gallega o portuguesa en particular? ¿Cree que los estudios medievales no han tenido en cuenta suficientemente el papel desempeñado por la traducción en la Península Ibérica?

J. C. Santoyo: Parece evidente que así es. Basta echar un vistazo a la historiografía medieval de la Península: las bibliotecas rebosan de apuntes (2008). Seu último título, La traducción medieval en la península ibérica, siglos III-XV, publicado em 2009, é fruto de numerosos anos de trabalho e o auge de toda uma trajetória de pesquisa em torno à história da tradução no Medievo da península ibérica.

Anna Gil: Em primeiro lugar, muito obrigado por ter escrito esta apaixonante história da tradução medieval na península ibérica. Com sua publicação, pareceme que não apenas se preenche um enorme vazio nas pesquisas, mas que ela se torna uma obra de referência inevitável para os estudos medievais, em geral, e para os estudos de tradução, em particular. Novamente, muitíssimo obrigado e felicidades por seu excelente trabalho.

Comecemos pelo final. $\mathrm{O}$ sr. termina seu livro colocando a seguinte questão: Até quando a história da tradução continuará ausente, como tem estado até então, das respectivas histórias da literatura, da ciência, da religião, da cultura medieval peninsular em geral, e da catalã, castelhana, galega ou portuguesa em particular? Acredita que os estudos medievais não consideraram suficientemente o papel desempenhado pela tradução na Península Ibérica?

J. C. Santoyo: Parece claro que é isso mesmo. Basta dar uma olhada na historiografia medieval da Península: as bibliotecas transbordam de 
volúmenes que tratan del arte, la religión, la política, las dinastías reales y guerras entre reinos, la población, la diplomacia, el comercio, la navegación y mil y un aspectos más del Medievo peninsular, pero muy raramente del papel que la traducción ha desempeñado en la mayoría de esas historias sectoriales, y menos aún en el desarrollo de las ideas y de la cultura medieval. Basten dos ejemplos: el investigador que lo desee hallará una vasta bibliografía sobre el marqués de Santillana: ediciones y reediciones de sus obras, casi todas con eruditos prólogos y notas, estudios críticos, históricos, biográficos y bibliográficos, documentación coetánea y demás, pero muy rara vez, si alguna, una monografía sobre su figura como impulsor directo de un amplísimo número de traducciones y como centro de todo un círculo nacional e internacional de traductores, de considerable repercusión literaria y cultural. O bien, como segundo ejemplo, en el mismo s. XV, el de la extraordinaria abundancia de traducciones de textos de condición religiosa, traducciones que Lola Badía considera de «tanta o més importància per a la formació de la llengua literària $\mathrm{i}$ del clima cultural de la tardor medieval que les de tema clàssic», pero que, sin embargo, como reconoce Charles B. Faulhaber, «a pesar de su popularidad, son textos que jamás se estudian hoy». Y es que, como ha escrito uno de los más conocidos teóricos de los Estudios de Traducción, Gideon Toury, «the role played by translation in the stimulation and dissemination of ideas... has been frequently over- volumes que tratam de arte, religião, política, dinastias reais e guerras entre reinos, comércio, navegação e mil e um aspectos mais do Medievo peninsular, porém muito raramente do papel que a tradução desempenhou na maioria dessas histórias setoriais, e menos ainda no desenvolvimento das ideias e da cultura medieval. Bastem dois exemplos: o pesquisador que deseje, encontrará uma vasta bibliografia sobre o marquês de Santillana: edições e reedições de suas obras, quase todas com eruditos prólogos e notas, estudos críticos, históricos, biográficos e bibliográficos, documentação coetânea e mais, porém raramente alguma monografia sobre seu papel como impulsor direto de um amplíssimo número de traduções e como centro de todo um círculo nacional e internacional de tradutores, de considerável repercussão literária e cultural. Ou ainda, como segundo exemplo, no mesmo século $\mathrm{XV}$, o da extraordinária abundância de traduções de textos de natureza religiosa, traduções que Lola Badía considera como de "tanta ou maior importância para a formação da língua literária e do clima cultural do outono medieval que os de tema clássico", porém que, no entanto, como reconhece Charles B. Faulhaber, "apesar de sua popularidade, são textos que não se estudam mais hoje." É que, como escreveu um dos mais conhecidos teóricos dos Estudos da Tradução, Gideon Toury, "o papel representado pela tradução na estimulação e disseminação de ideias... tem sido frequentemente negligenciado e raramente reconhecido". E esse é precisamen- 
looked and seldom acknowledged». $\mathrm{Y}$ ese es precisamente el caso.

Anna Gil: ¿Podría explicar brevemente por qué «al extenso mosaico de más de mil años» de la historia de la traducción medieval en la Península Ibérica le faltan tantas teselas? ¿En qué disciplinas o lenguas estas teselas están más ausentes?

J. C. Santoyo: Yo diría que pueden apuntarse al menos dos razones probables, si no posibles: en primer lugar, por la carencia de estudios, que sólo últimamente ha comenzado a remediarse; si ya la historia de la traducción en general ha estado prácticamente olvidada hasta nuestros mismos días, mucho más lo ha estado esa historia por lo que respecta a los tiempos medievales. Y en segundo lugar, por la propia condición de la documentación medieval, tan fragmentaria: la historia del Medievo, en su conjunto, es un gran tapiz, pero en su urdimbre faltan muchos hilos, y se aprecian amplios huecos y desgarros. Lo cierto es que disponemos tan sólo de un «conocimiento mutilado», como dice Paul Veyne, de la traducción medieval en la Península Ibérica, y así lo subrayo desde la primera página del libro. $\mathrm{Si}$ se me permite, vuelvo a decir aquí lo que allí digo: Los textos están ahí, unos y otros, originales y traducciones (cuando están, naturalmente, porque muchos han desaparecido y sólo sabemos de ellos por referencias); pero más allá de los propios textos, en muy raras ocasiones nos es dado acceder a conocimientos meta-, co- y con-tex- te o caso.

Anna Gil: Poderia explicar brevemente por que faltam tantas peças "no extenso mosaico de mais de mil anos" da história da tradução medieval na Península Ibérica? Em que disciplinas ou línguas estas peças estão mais ausentes?

J. C. Santoyo: Eu diria que se podem assinalar ao menos duas razões prováveis, se não possíveis: em primeiro lugar, pela carência de estudos, que apenas ultimamente começou a se remediar; se, pois, a história da tradução em geral ficou praticamente esquecida até nossos dias, muito mais ficou essa história em relação aos tempos medievais. E em segundo lugar, pela própria condição da documentação medieval, tão fragmentária: a história do Medievo, em seu conjunto, é um grande tapete, porém em sua urdidura faltam muitos fios, e se percebem buracos grandes e rasgos. O certo é que dispomos apenas de um "conhecimento mutilado", como diz Paul Veyne, da tradição medieval na Península Ibérica, e isso destaco desde a primeira página do livro. Se me permite, volto a dizer aqui o que digo ali: Os textos estão aí, uns e outros, originais e traduções (quando estão, naturalmente, porque muitos desapareceram e apenas sabemos deles por referências); porém mais além dos próprios textos, em ocasiões muito raras nos é dado chegar a conhecimentos meta-, coe con-textuais: por solicitação de quem se traduzia, por que, como e 
tuales: a instancias de quién se traducía, por qué, cómo y dónde se llevó a cabo la traducción, quién la hizo, qué competencia textual, temática, lingüística o cultural poseía, con qué medios contaba, qué colaboradores tuvo, de qué original(es) dispuso, a qué lector(es) destinaba su trabajo...; datos, en definitiva, de condición histórica, en muchos casos tan importantes como los de condición lingüística. De ahí, por ejemplo, el gran vacío traductor de los ss. VII, VIII y IX, la penuria de datos en los siguientes ss. X y XI, el silencio traductor gallego-portugués hasta casi el s. XIV, el vacío traductor que envuelve a la lengua vasca durante toda la Edad Media, la ausencia de información, salvo detalles dispersos, sobre la traducción oral, o interpretación, que ineludiblemente hubo de practicarse a lo largo de todo el Medievo, nuestro desconocimiento casi total de la traducción de índole diaria, no erudita, sino estrictamente práctica en su misma cotidianidad...

Anna Gil: Sorprende descubrir la escasez de traducciones del árabe al latín en el s. XI, un siglo en el que precisamente la producción cultural en lengua árabe alcanza su apogeo. De hecho, la época de los Taifas es el período más fructífero no sólo de la literatura andalusí en lengua árabe (con poetas $\mathrm{e}$ intelectuales de la talla de Ibn Zaydún o Ibn Ammar, por citar sólo dos), sino también del pensamiento, la medicina o la historia en esa lengua (con intelectuales como Ibn Hazm o Avicena, entre otros). ¿Cómo explica esta falta de tra- onde se realizou a tradução, quem a fez, que competência textual, temática, linguística ou cultural possuía, com que meios contava, que colaboradores teve, de que original(is) dispôs, a que leitor(es) destinava seu trabalho...; dados, por certo, de natureza histórica, em muitos casos tão importantes como os de natureza linguística. Daí, por exemplo, o grande vazio tradutor dos séculos VII, VIII e IX, a penúria de dados nos séculos seguintes, $\mathrm{X}$ e XI, o silêncio tradutor galego-português até quase o século XIV, o vazio tradutor que envolve a língua basca durante toda a Idade Média, a ausência de informação, exceto detalhes dispersos, sobre a tradução oral, ou interpretação, que inevitavelmente foi praticada ao longo de todo o Medievo, nosso desconhecimento quase total da tradução de caráter diário, não erudito, mas estritamente prático em sua mesma cotidianidade...

Anna Gil: Surpreende descobrir a escassez de traduções do árabe ao latim no século XI, um século em que precisamente a produção cultural em língua árabe atinge seu apogeu. De fato, a época dos Taifas é o período mais frutífero não só da literatura andaluz em língua árabe (com poetas e intelectuais do porte de Ibn Zaydún ou Ibn Ammar, para citar apenas dois), mas também do pensamento, da medicina ou da história nessa língua (com intelectuais como Ibn Hazm ou Avicena, entre outros). Como explica esta falta 


\section{ducciones?}

J. C. Santoyo: No hay modo de explicar tal escasez, o al menos yo no sé explicarla. Puesto a elucubrar, y dado que la traducción es el resultado de determinada competencia interlingüística y de intereses y contactos interculturales, uno sospecha que ni tal competencia en árabe fue común aquel siglo en la sociedad cristiana de la Península, ni la competencia en latín lo fue en la sociedad musulmana. Por otro lado, el interés por la traducción únicamente lo sintió en el Medievo la sociedad cristiana (y en mucha menor medida ciertas comunidades judías): eran textos en árabe los que se vertían al latín, no a la inversa. La sociedad musulmana peninsular nunca se interesó por los textos de los cristianos: tan sólo hay noticia de una obra latina traducida en la Península al árabe, las Historiae adversus paganos, de Paulo Orosio. Es evidente, pues, que ese interés cristiano no se dio a lo largo de todo el s. XI y que sólo comenzó a manifestarse en los primeros decenios del siguiente $\mathrm{s}$. XII. ¿Las causas? Muy probablemente, el propio estado de la sociedad cristiana de la Península, ocupada aquel siglo más en cuestiones de supervivencia que de ciencia o cultura (primum vivere...), ocupada también en sus propias rencillas, que no fueron escasas, y en contrarrestar los continuos ataques musulmanes que llegaban desde el sur, entre ellos los bien conocidos de Almanzor, que a lo largo de casi veinticinco años asoló todo el norte de la Península, desde Barcelona a Santiago de Compostela.

\section{de traduções?}

J. C. Santoyo: Não há como explicar tal escassez, ou pelo menos eu não sei explicar. Pondo-se a refletir, e considerando que a tradução é o resultado de determinada competência interlinguística e de interesses e contatos interculturais, podese suspeitar de que nem tal competência em árabe foi comum naquele século na sociedade cristã da Península, nem a competência em latim o foi na sociedade muçulmana. Por outro lado, o interesse pela tradução no Medievo foi unicamente sentido pela sociedade cristã (e em muito menor medida por certas comunidades judaicas): eram textos em árabe os que se vertiam ao latim e não o inverso. A sociedade muçulmana peninsular nunca se interessou pelos textos dos cristãos: há notícia apenas de uma obra latina latina traduzida ao árabe na Península, as Historiae adversus paganos, de Paulo Orosio. É evidente, pois, que esse interesse cristão não se deu ao longo de todo o século XI e que somente começou a se manifestar nas primeiras décadas do século XII. As causas? Muito provavelmente, o próprio estado da sociedade cristã da Península, ocupada naquele século mais com questões de sobrevivência do que de ciência ou de cultura (primum vivere...), ocupada também com suas próprias contendas, que não foram poucas, e com resistir aos contínuos ataques muçulmanos que chegavam do sul, entre eles os bem conhecidos de Almançor, que durante quase 25 anos assolou todo o norte da Península, de Barcelona a Santiago de Com- 
Queda, como último recurso explicativo, la posibilidad de que seamos nosotros los que desconozcamos, por falta de documentación, la realidad de los hechos. Vernet ya dice que «hay muy pocos testimonios, por no decir ninguno», de la actividad traductora de ese siglo. Poco antes Lemay aseguraba también que «durante todo el s. XI no hay prácticamente ningún vestigio de intercambio científico o filosófico entre latinos y árabes o mozárabes». Pero que haya muy pocos testimonios, por no decir ninguno, o que no haya prácticamente ningún vestigio, puede que tan sólo se deba a que unos y otros se han perdido, o aún no han sido hallados. Que, personalmente, no creo que sea el caso.

Anna Gil: En la primera parte del libro usted se refiere en varias ocasiones al papel preponderante que desempeñó el scriptorium del monasterio de Santa Maria de Ripoll en el s. X. ¿Podría resumir en algunas líneas el tipo de trabajo que se realizó en Ripoll, así como el porqué de su importancia?

J. C. Santoyo: De Ripoll es muy poco lo que sabemos, algo más lo que deducimos y bastante más lo que suponemos. Ni siquiera sabemos si allí hubo un scriptorium como tal, en el que se hicieran traducciones del árabe al latín. Lo que sí sabemos es que la biblioteca del monasterio contaba a finales del s. X con 66 códices, que pocos años después eran 121, y que a la muerte del abad Oliva, en 1046, la biblioteca conta- postela. Resta, como último recurso explicativo, a possibilidade de que sejamos nós os que desconheçamos, por falta de documentação, a realidade dos fatos. Vernet já dizia que "há muito poucos testemunhos, para não dizer nenhum", da atividade tradutora desse século. Pouco antes Lemay afirmava também que "durante todo o século XI não há praticamente nenhum vestígio de intercâmbio científico ou filosófico entre latinos e árabes ou moçárabes". Porém, que haja muito poucos testemunhos, para não dizer nenhum, ou que não haja praticamente nenhum vestígio, pode que se deva somente a que uns e outros se tenham perdido, ou ainda não tenham sido encontrados. $\mathrm{O}$ que, pessoalmente, não acredito que seja o caso.

Anna Gil: Na primeira parte do livro, o sr. se refere em várias ocasiões ao papel preponderante que desempenhou o scriptorium do mosteiro de Santa Maria de Ripoll no século $X$. Poderia resumir em poucas linhas o tipo de trabalho que se realizou em $\mathbf{R i}$ poll, bem como o porquê de sua importância?

J. C. Santoyo: Sobre Ripoll sabemos muito pouco, um pouco mais o que deduzimos e muito mais o que supomos. Nem ao menos sabemos se houve alí um scriptorium como tal, no qual se fizeram traduções do árabe ao latim. O que sabemos ao certo é que a biblioteca do mosteiro contava no final do século $\mathrm{X}$ com 66 códices, que poucos anos depois eram 121, e que, quando da morte do abade Oliva, em 1046, a biblio- 
ba ya con 246 volúmenes, número ciertamente muy notable para la época. La importancia de Ripoll en la historia de la traducción medieval es la de una condición pionera, porque entre aquellos primeros 66 códices de los últimos decenios del siglo X había al menos trece traducciones o reelaboraciones latinas de originales árabes, todas de carácter práctico o «científico»: tratados sobre el astrolabio, sobre el clima, sobre geometría, sobre relojes..., tratados que nos han llegado en un estado muy fragmentario (102 folios en total) y que hay que considerar como restos supervivientes de una compilación sin duda mucho más amplia y completa. ¿Se hicieron tales traducciones en el propio monasterio, o fue su biblioteca únicamente el lugar donde acabaron depositadas y guardadas? No lo sabemos. Cuando en el 984 Gerberto de Aurillac, futuro papa Silvestre II, necesitó en Reims un tratado sobre la multiplicación y división de los números traducido por cierto Joseph ispano, se lo pidió al obispo de Gerona, Miró Bonfill; y cuando años después se interesó por un tratado de astrología, se lo pidió a cierto Lupitus Barchinonensis, probablemente el arcediano de la catedral de Barcelona Sunifred Llobet. ¿Cabe deducir de estos pocos datos que en Ripoll hubo un scriptorium y que en él se hicieron aquellas traducciones del árabe al latín? Puede resultar arriesgado.

Anna Gil: En uno de los pasajes más interesantes, a la vez que controvertidos, de su libro, usted niega la existencia de las famosas es- teca contava com 246 volumes, número certamente notável para a época. A importância de Ripoll na história da tradução medieval é a de uma condição pioneira, porque entre aqueles primeiros 66 códices das últimas décadas do século $\mathrm{X}$ havia ao menos 13 traduções ou reelaborações latinas de originais árabes, todas de caráter prático ou "científico": tratados sobre o astrolábio, sobre o clima, sobre geometria, sobre relógios..., tratados que nos chegaram num estado muito fragmentário (102 fólios no total) e que devem ser considerados como restos sobreviventes de uma compilação sem dúvida muito mais ampla e completa. Fizeram-se tais traduções no próprio mosteiro, ou sua biblioteca foi unicamente o lugar onde acabaram depositadas e guardadas? Não sabemos. Quando, em 984, Gerbert d'Aurillac, futuro papa Silvestre II, necessitou, em Reims, de um tratado sobre a multiplicação e a divisão dos números, traduzido por um certo Joseph Ispano, solicitou-o ao bispo de Girona, Miró Bonfill; e quando, anos depois, se interessou por um tratado de astrologia, solicitou-o a um certo Lupitus Barchinonensis, provavelmente o arquidiácono da catedral de Barcelona Sunifred Llobet. Pode-se deduzir destes poucos dados que em Ripoll houve um scriptorium e que nele se fizeram aquelas traduções do árabe ao latim? Pode ser arriscado.

Anna Gil: Numa das passagens mais interessantes, e ao mesmo tempo controvertidas, de seu livro, o sr. nega a existência das fa- 
cuelas de traductores de Toledo $y$ de Bagdad (Bait al-Hikma). ¿Qué es lo que, a su parecer, motivó la creación de ambos mitos? ¿Por qué la «bola de nieve» de la que usted habla se originó en ciudades como Toledo y Bagdad, y no en otras localidades de la Península? ¿Cuáles fueron, según usted, las ciudades, tanto peninsulares como de fuera de la Península, en las que se desarrolló de forma más notoria la traducción durante el período medieval?

J. C. Santoyo: No hay fácil respuesta a tanta pregunta. ¿Qué motivó la creación de ambos mitos? En lo que a España se refiere, probablemente cierta inveterada admiración por todo lo que llega con etiqueta ultrapirenaica. En el caso de Toledo, la «cronología» del mito de una escuela de traductores se inicia en Francia, y a grandes rasgos está bastante clara: ninguna mención, ni la más mínima, a tal entidad hasta comienzos del s. XIX, la alusión primera (1819, 1843) del francés Jourdain a un «collège de traducteurs», su adopción por Renan en 1852, luego en Alemania por Rose en 1874, y finalmente su paso a España con Menéndez Pelayo en 1881 y posteriormente ya en el s. XX, con Menéndez Pidal. En cuanto a la inexistencia de una escuela de traductores en Bagdad, son voces mucho más autorizadas que la mía las que así lo aseguran. Hunayn ibn Ishaq (+873), quizá el más notable traductor (en Bagdad) de todos los tiempos, en ningún momento menciona a lo largo de su extensísima obra, original y traducida, la existencia de una es- mosas escolas de tradutores de Toledo e de Bagdá (Bait al-Hikma). $O$ que é que, a seu ver, levou à criação de ambos os mitos? Por que a "bola de neve" de que o sr. fala se originou em cidades como Toledo e Bagdá, e não em outras localidades da Península? Quais foram, segundo o sr., as cidades, tanto peninsulares como de fora da Península, nas quais se desenvolveu de forma mais evidente a tradução durante o período medieval?

J. C. Santoyo: Não há resposta fácil a tantas perguntas. O que motivou a criação de ambos os mitos? No que se refere à Espanha, provavelmente uma certa admiração antiga por tudo o que seja ultrapirenaico. No caso de Toledo, a "cronologia" do mito de uma escola de tradutores começa na França, e de um modo geral está bastante clara: nenhuma menção, nem a mais mínima, a tal entidade até inícios do século XIX, quando da primeira alusão $(1819,1843)$ pelo francês Jourdain a um "collège de traducteurs", sua adoção por Renan, em 1852, em seguida na Alemanha por Rose, em 1874, e finalmente sua passagem pela Espanha com Menéndez Pelayo em 1881 e posteriormente, já no século XX, com Menéndez Pidal. Quanto à inexistência de uma escola de tradutores em Bagdá, são vozes muito mais autorizadas que a minha que assim o asseguram. Hunayn ibn Ishaq $(+873)$, talvez o mais ilustre tradutor (em Bagdá) de todos os tempos, em nenhum momento menciona ao longo de sua vastíssima obra, original e traduzi- 
cuela de traductores en aquella ciudad. La crítica actual más sólida rechaza asimismo tal existencia, y quien de ello discrepe tendrá primero que contrarrestar los argumentos de Myriam Salama-Carr (La traduction à l'époque abbaside, 1990) o de Dimitri Gutas (Greek Thought, Arabic Culture: The Graeco-Arabic Translation Movement in Bagdad, 1998). Entonces, ¿Qué fue lo que motivó la creación de ambos mitos? Supongo que en uno y otro caso la presencia en ambas ciudades y en determinado momento (Bagdad s. IX, Toledo s. XII) de cierto número de traductores que allí llevaron a cabo su tarea, a veces en solitario, otras veces «a duo». Si a esa simultaneidad en el tiempo se la quiere llamar «escuela», bien está; pero sea cada cual responsable de sus propias afirmaciones. Y sobre la última de sus preguntas: la Edad Media es un período tan extenso que casi no hay localidad de la época en la que, al menos en Europa, no se halle(n) algún(os) traductor(es), y ello desde Braga, en un extremo del continente, hasta Constantinopla en el otro, y desde Oxford en el norte hasta Sicilia en el sur. Aun así, creo que, por distintas razones, han entrado en la historia medieval de la traducción: en el s. VI, Squillace, en la Catania italiana, con la primera y ejemplar «casa del traductor», Vivarium, que allí estableciera Casiodoro; en el s. XI, Salerno, con, entre otras, la figura sobresaliente de Constantino el Africano; obviamente Tarazona, Toledo, Barcelona y Tudela (i) en el s. XII peninsular; da, a existência de uma escola de tradutores naquela cidade. A crítica atual mais sólida contesta também tal existência, e quem discordar terá de opor-se aos argumentos de Myriam Salama-Carr (La traduction à l'époque abbaside, 1990) ou de Dimitri Gutas (Greek Thought, Arabic Culture: The Graeco-Arabic Translation Movement in Bagdad, 1998). Então, o que foi que motivou a criação de ambos os mitos? Suponho que, num e noutro caso, em ambas as cidades e em determinado momento (Bagdá século IX, Toledo século XII), a presença de um certo número de tradutores que realizaram ali sua tarefa, algumas vezes sozinhos, outras em dupla. Caso se queira chamar de "escola" essa simultaneidade no tempo, está bem; porém, cada um se responsabilize por suas afirmações. E sobre a última de suas perguntas: a Idade Média é um período tão vasto que quase não há localidade da época na qual, ao menos na Europa, não se encontre (m) algum(s) tradutor(es), e isso de Braga, num extremo do continente, a Constantinopla, no outro, e de Oxford, no norte, a Sicília, no sul. Ainda assim, acredito que, por razões distintas, entraram na história medieval da tradução: no século VI, Squillace, na Calábria ${ }^{2}$ italiana, com a primeira e exemplar "casa do tradutor", o Vivarium, ali fundado por Cassiodoro; no século XI, Salerno, entre outras, com a figura extraordinária de Constantino o Africano; obviamente Tarazona, Toledo, Barcelona e Tudela no século XII peninsular; na passagem dos

\footnotetext{
${ }^{2}$ Parece haver um equívoco no texto original: a cidade de Squillace, onde Cassiodoro nasceu, e, entre 554-560, fundou o Vivarium, fica na Calábria.
} 
a caballo de los ss. XII-XIII, Lunel, en el Languedoc, con la familia judía de los Tibbon; en el s. XIII, Palermo, en Sicilia, y de nuevo Toledo, y también Murcia y Sevilla, en la Península Ibérica...

Anna Gil: Después de leer detenidamente todo el pasaje dedicado a la extraordinaria figura de Gerardo de Cremona (1114-1187), una se pregunta si el hecho de haber impartido enseñanzas en la escuela catedralicia (magister), el hecho de haber traducido más de $\mathbf{7 0}$ obras del árabe al latín y el hecho de contar con un cierto número de colaboradores (socii) para algunas de sus traducciones no contribuyó a construir la idea de una «escuela» de traductores de Toledo, hecho que además un siglo más tarde se vería apoyado por la presencia en Toledo de traductores como Marcos de Toledo, Salio de Padua, Miguel Escoto, Juan de Toledo o Hermann el Alemán.

J. C. Santoyo: Es muy posible, sí, que todo ello haya contribuido a crear el tópico de tal «escuela». Pero, caso de haberla, en una «escuela» así ha de darse al menos una presencia simultánea de cierto número, y no escaso, de traductores, y cierta interrelación entre ellos. Y desde luego tal presencia simultánea no la hubo en Toledo, donde sí asistimos a una presencia sucesiva de traductores, y a escasísimos casos de colaboración. Así, Iohannes Hispalensis reside en Toledo aproximadamente 20 años (ca. 1136-ca. 1155), coincidiendo allí muy poco tiempo con un joven Domingo Gun- séculos XII para XIII, Lunel, em Languedoc, com a família judaica dos Tibbon; no século XIII, Palermo, na Sicília, e de novo Toledo, e também Múrcia e Sevilha, na Península Ibérica...

Anna Gil: Depois de ler detidamente toda a passagem dedicada à extraordinária figura de Gerardo de Cremona (1114-1187), pergunta-se se $o$ fato de haver ministrado aulas na escola catedralícia (magister), o fato de haver traduzido mais de $\mathbf{7 0}$ obras do árabe ao latim e o fato de contar com um certo número de colaboradores (socii) para algumas de suas traduções não contribuiu para construir a ideia de uma "escola" de tradutores de Toledo, fato que, além disso, seria fortalecido um século mais tarde pela presença em Toledo de tradutores como Marcos de Toledo, Salio de Pádua, Miguel Escoto, Juan de Toledo ou Hermann o Alemão.

J. C. Santoyo: É bem possível, sim, que tudo isso tenha contribuído para criar o tópico de uma tal "escola". Porém, no caso de havê-la, numa "escola" assim há de dar-se a presença simultânea de um certo número, e não pequeno, de tradutores, e uma certa interrelação entre eles. E certamente tal presença simultânea não houve em Toledo, onde, porém, assistimos a uma presença sucessiva de tradutores, e a raríssimos casos de colaboração. Assim, Iohannes Hispalensis reside em Toledo por aproximadamente 20 anos (ca. 1136 - ca. 1155), coincidindo ali muito pouco tempo com um jo- 
disalvo, que llega a la ciudad a mediados de siglo y no fallecerá hasta ca. 1190; Gerardo de Cremona llega a Toledo en torno a 1150 y allí reside más de 25 años, hasta su fallecimiento en 1187, sin que en ningún momento mencione a otros traductores; tras cursar estudios de medicina en Montpellier, Marcos de Toledo traduce en su ciudad entre ca. 1180 y 1213 , sin que tampoco hable de ningún otro colega traductor; Miguel Escoto tan sólo estuvo cinco años en Toledo, entre 1214? y 1219?; menos tiempo aún estuvo el italiano Salio de Padua, del que sólo consta con seguridad su estancia en 1218; y mucho más tardío aún es Hermann el Alemán, que no conoció a ninguno de los anteriores, dado que sus traducciones están fechadas en 1240-46 y en 1256... A lo largo de más de un siglo, pues, en Toledo parece haber habido una sucesión de muy pocos traductores, pero en ningún caso una escuela, ni siquiera lo que podríamos denominar «un grupo».

Anna Gil: Usted llama la atención sobre la ausencia de fondos árabes a lo largo de todo el s. XII (p. 136 y 137), lo que le lleva a preguntarse: «¿De dónde se obtuvieron tantos textos en árabe como los que se tradujeron del latín durante aquel siglo?». Para ilustrar su reflexión, aporta los testimonios de clérigos, arcedianos, capiscoles y nobles castellanos (como la condesa Mumadona Dias), y cita bibliotecas, armarios $\mathbf{y}$ arcas, todos ellos situados en territorios bajo control cristiano, to- vem Domingo Gundisalvo, que chega à cidade no meio do século e só falecerá por volta de 1190; Gerardo de Cremona chega a Toledo em torno de 1150 e reside ali mais de 25 anos, até sua morte em 1187, sem que em nenhum momento mencione outros tradutores; depois de estudar medicina em Montpellier, Marcos de Toledo traduz em sua cidade entre ca. 1180 e 1213 , sem que tampouco fale de qualquer outro colega tradutor; Miguel Escoto esteve apenas 5 anos em Toledo, talvez entre 1214 e 1219; menos tempo ainda esteve o italiano Salio de Pádua, do qual apenas consta com certeza sua estada em 1218; e, ainda muito mais tarde, Hermann o Alemão, que não conheceu nenhum dos anteriores, uma vez que suas traduções estão datadas em 1240-46 e em $1256 \ldots$ Ao longo de mais de um século, pois, em Toledo parece ter havido uma sucessão de muito poucos tradutores, porém em nenhum caso uma escola, nem sequer o que poderíamos denominar "um grupo".

Anna Gil: O sr. chama a atenção para a ausência de um acervo de obras árabes ao longo de todo o século XII (p. 136-137), o que o leva a se perguntar: "De onde se obtiveram tantos textos em árabe como os que se traduziram do latim durante aquele século?" Para ilustrar sua reflexão, apresenta testemunhos de clérigos, arquidiáconos, chantres e nobres castelhanos (como a condessa Mumadona Dias), e cita bibliotecas, armários e arcas, todos eles situados em territórios sob controle cris- 
dos ellos con textos latinos. Yo me pregunto si esa falta de libros en árabe no se explica por el hecho de que los originales se hallaran en bibliotecas, mezquitas y cortes de los distintos reinos de taifas. ¿Podría decirnos si hay sobre ellos algún tipo de documentación?

J. C. Santoyo: No hubo, al parecer, falta de libros en árabe en los territorios cristianos reconquistados, puesto que muchos fueron los que en aquel siglo, y en el siguiente, se vertieron al latín. Lo que escasea es la documentación sobre las bibliotecas de los reinos de taifas en los ss. XI y XII, sobre lo que de ellas pervivió y sobre el trasvase de tales libros a manos cristianas, y en particular a las manos de los traductores. Es una documentación que nos llega a cuentagotas. En 1087 Paterno, obispo de Coimbra (reconquistada en 1064), dejó en testamento «un libro de cánones escrito en árabe, y otros libros hispalenses» (quizá la colección de cánones y decretos pontificios traducidos del latín al árabe por el presbítero mozárabe Vincentius ca. 1050). En los primeros decenios del s. XII el entonces joven Iohannes Hispalensis reconoce haberse trasladado desde la Limia gallega a otras partes de España (Hispanas partes) en busca de libros de astronomía, y haber vivido en esos lugares «entre gentes desalmadas que no creían en Dios», y allí haber leído y releído tales libros de astronomía, «como es el caso de los cursos de los planetas, y otros que también parecían referirse a ese arte». ¿Alude a alguno de los tão, todos eles com textos latinos. Eu me pergunto se essa falta de livros em árabe não se explica pelo fato de que os originais foram encontrados em bibliotecas, mesquitas e cortes dos distintos reinos de taifas. Poderia nos dizer se há algum tipo de documentação sobre eles?

J. C. Santoyo: Não houve, parece, falta de livros em árabe nos territórios cristãos reconquistados, uma vez que são muitos os que foram traduzidos ao latim naquele século e no seguinte. O que escasseia é a documentação sobre as bibliotecas dos reinos de taifas, nos séculos XI e XII, sobre o que sobreviveu delas e sobre a transferência de tais livros para mãos cristãs, e, em particular, para as mãos dos tradutores. É uma documentação que nos chega a conta-gotas. Em 1087, Paterno, bispo de Coimbra (reconquistada em 1064), deixou em testamento "um livro de cânones escrito em árabe, e outros livros hispalenses" (talvez a coleção de cânones e decretos pontifícios traduzidos do latim ao árabe pelo presbítero moçárabe Vicentius, ca. 1050). Nas primeiras décadas do século XII, o então jovem Iohannes Hispalensis admite ter-se mudado da Límia galega a outras partes da Espanha (Hispanas partes) em busca de livros de astronomia, e ter vivido nesses lugares "entre pessoas desalmadas que não acreditavam em Deus", e ali ter lido e relido tais livros de astronomia, "como é o caso dos cursos dos planetas, e outros que também pareciam referir-se a essa arte". Alude a algum dos territórios das taifas muçulmanas, e a 
territorios de las taifas musulmanas, y a sus bibliotecas? Parece lo más probable, y personalmente no me caben dudas al respecto. Pero carecemos de más detalles. A su vez, Charles Burnett apunta la posibilidad de que los originales árabes que Hugo de Santalla tradujo en Tarazona procedieran de la biblioteca de los Banu Hud, reyezuelos de la pequeña taifa de Rueda de Jalón entre 1110 y 1131, biblioteca (in Rotensi armario) quizá disponible a partir de esa última fecha, cuando el último representante de la dinastía, Ahmad Sayf al-Dwala (Zafadola), prestó vasallaje a Alfonso VII y entregó Rueda al monarca cristiano. Pero tan sólo es, de nuevo, una conjetura. Los socii de Gerardo de Cremona aseguran que en Toledo, taifa reconquistada en 1085 , todavía un siglo después había «abundancia de libros en árabe sobre todos los saberes». Datos demasiado nebulosos en todos los casos. Pero sobre las bibliotecas que pudo haber en las cortes y mezquitas de las taifas de Murcia, Albarracín, Niebla, Sevilla, Almería y demás reconozco que nada sé, salvo lo poco que de ellas ya dijeron Julián Ribera, Menéndez Pidal o Sánchez Albornoz.

Anna Gil: Vista la gran cantidad de traductores (dieciséis que se conozcan) y obras traducidas en el entorno cortesano de Alfonso $X$ el Sabio, el lector puede que se pregunte si existió en la Edad Media peninsular una actividad traductora mayor - por número e importancia- que la que hubo en aquella corte. Por otra parte, isería exagerado afirmar que la tra- suas bibliotecas? Parece muito provável, e pessoalmente não me restam dúvidas a respeito. Porém, carecemos de mais detalhes. Por sua vez, Charles Burnett indica a possibilidade de que os originais árabes traduzidos por Hugo de Santalla em Tarazona provieram da biblioteca dos Banu Hud, reizinhos da pequena taifa de Rueda de Jalón, entre 1110 e 1131, biblioteca (in Rotensi armario) talvez disponível a partir da última data, quando o último representante da dinastia, Ahmad Sayf al-Dwala (Zafadola), prestou vassalagem a Alfonso VII e entregou Rueda ao monarca cristão. Porém, é apenas, de novo, uma conjectura. Os socii de Gerardo de Cremona asseguram que, em Toledo, taifa reconquistada em 1085, ainda um século depois havia "abundância de livros em árabe sobre todos os saberes". Dados demasiado nebulosos em todos os casos. Porém, sobre as bibliotecas que puderam existir nas cortes e mesquitas das taifas de Múrcia, Albarracin, Niebla, Sevilha, Almeria e outras, reconheço que não sei nada, exceto o pouco que já disseram sobre elas Julián Robera, Menéndez Pidal ou Sánchez Albornoz.

Anna Gil: Dada a grande quantidade de tradutores (16 são conhecidos) e obras traduzidas no entorno da corte de Alfonso X o Sábio, o leitor talvez se pergunte se existiu na Idade Média peninsular uma atividade tradutora maior em número e em importância do que a que houve naquela corte. Por outra parte, seria exagerado afirmar que a tradução foi a ati- 


\section{ducción fue la actividad cultural que más impulsó este monarca?}

J. C. Santoyo: Depende de qué entendamos por importancia, y a qué se la demos. Desde luego, mayor trascendencia internacional alcanzaron las traducciones peninsulares del s. XII (todas al latín), muchas de las cuales siguieron copiándose en los siglos siguientes, e imprimiéndose luego hasta bien entrado el s. XVI. Numerosos ejemplares manuscritos e impresos de tales traducciones se hallan todavía hoy en las bibliotecas más importantes de Europa y América. En cambio, las traducciones del entorno del rey Alfonso, de escasa trascendencia internacional dado que la mayoría lo fueron al castellano, resultan ser de notable importancia nacional, como bien sabe, entre otros, cualquier historiador de la lengua castellana. Por lo que respecta al número de textos traducidos, de nuevo los del s. XII superan con mucho a los del entorno cortesano alfonsino. Y más numerosas que las de este monarca son también las traducciones que en la primera mitad del s. XV se llevaron a cabo por indicación y encargo directo del marqués de Santillana. En cuanto a su pregunta, creo que no, que no resulta exagerado afirmar que la traducción fue la actividad cultural que más impulsó Alfonso el Sabio: hay que tener en cuenta que, además de las versiones exentas, buena parte de los textos históricos hechos compilar por el monarca, sobre todo la General Estoria y la Crónica General, están en gran medida compuestos por material traducido inserto, procedente de vidade cultural mais impulsionada por este monarca?

$J$. C. Santoyo: Depende do que entendemos por importância, e a que a atribuímos. Por certo, maior transcendência internacional alcançaram as traduções peninsulares do século XII (todas em latim), muitas das quais continuaram a ser copiadas nos séculos seguintes, e impressas depois até bem avançado o século XVI. Numerosos exemplares manuscritos e impressos de tais traduções se encontram ainda hoje nas bibliotecas mais importantes da Europa e da América do Norte. Por outro lado, as traduções do entorno do rei Alfonso, de pouca transcendência internacional, uma vez que a maioria foi feita em castelhano, são de grande importância nacional, como bem sabe, entre outros, qualquer historiador da língua castelhana. Com relação ao número de textos traduzidos, de novo os do século XII superam em muito os do entorno da corte alfonsina. E mais numerosas que as deste monarca são também as traduções realizadas na primeira metade do século XV por recomendação e encargo direto do marquês de Santillana. Quanto à sua pergunta, acredito que não, que não é exagerado afirmar que a tradução foi a atividade cultural mais impulsionada por Alfonso o Sábio: devese levar em conta que, além das versões isentas [modernizadas e não anotadas], boa parte dos textos históricos que o monarca fez compilar, sobretudo a General Estoria e a Crónica General, estão em grande medida compostos por material traduzido inserto, procedente de origi- 
originales árabes y/o latinos (Lucano, Orosio, san Isidoro, Plinio, san Jerónimo, etc.).

Anna Gil: Pasemos ahora a hablar del a menudo ignorado alcance cultural de que gozó la ciudad de Murcia durante buena parte del s. XIII. ¿A qué se debió este florecimiento murciano de las artes y las letras? ¿Cuánto tiempo duró y por qué ha quedado relegado a un segundo plano, después de ciudades como Toledo o Burgos?

J. C. Santoyo: Se debió, sin duda, a la conjunción de tres distintos factores: un importante sustrato cultural previo en la taifa de Murcia, la frecuente residencia allí de Alfonso X el Sabio y la coincidencia en el tiempo (segunda mitad del s. XIII) de varias instituciones y personas. En Murcia pasó Alfonso X largas temporadas en 1254, 1257, 1270, 1272-73, etc., quizá porque, como dice el propio monarca, «amamos et deuemos querer este regno entre todos los otros»». Nada extraña, pues, que en Murcia y en Cartagena sitúe el rey varias de sus Cantigas. Y que el monarca dotara allí un centro de estudios en el que Mohamed ibn Ahmed Abubequer al-Ricotí enseñó muchos años medicina, lógica, geometría y filosofía, y lo hiciera indistintamente en árabe, romance o latín, porque sus estudiantes eran indistintamente musulmanes, judíos y cristianos. Pero es que también en Murcia fundaron los dominicos en 1265 un "studium arabicum et hebraicum», y a él es probable que pertenecieran los frailes Domingo nais árabes e/ou latinos (Lucano, Orósio, são Isidoro, Plínio, são Jerônimo, etc.).

Anna Gil: Falemos agora do comumente ignorado alcance cultural de que a cidade de Múrcia gozou durante boa parte do século XIII. A que se deveu este florescimento murciano das artes e das letras? Quanto tempo durou e por que ficou relegado a um segundo plano, atrás de cidades como Toledo ou Burgos?

J. C. Santoyo: Deveu-se, sem dúvida, à conjunção de três diferentes fatores: um importante substrato cultural prévio na taifa de Múrcia, a residência ali frequente de Alfonso $\mathrm{X}$ o Sábio e a coincidência no tempo (segunda metade do século XIII) de várias instituições e pessoas. Alfonso $\mathrm{X}$ passou longas temporadas em Múrcia em 1254, 1257, 1270, 1272-73, etc., talvez porque, como diz o próprio monarca, "amamos e devemos querer este reino entre todos os outros". Não admira, pois, que o rei situe várias de suas Cantigas em Múrcia e em Cartagena. E que o monarca tenha financiado ali um centro de estudos, no qual Mohamed ibn Ahmed Abubequer alRicotí ensinou por muitos anos medicina, lógica, geometria e filosofia, e o fazia indistintamente em árabe, romance ou latim, porque seus estudantes eram indistintamente muçulmanos, judeus e cristãos. Porém, é que também em Múrcia os dominicanos fundaram, em 1265, um "studium arabicum et hebraicum", e provavelmente a ele pertenceram os 
Marroquino y Rufino Alejandrino, traductores uno y otro al latín de varios tratados árabes de medicina. $\mathrm{Y}$ de Cartagena fue primer obispo desde 1250 el propio confesor del monarca, fray Pedro Gallego, que tradujo o mandó traducir del árabe al latín varias obras de medicina, una Summa de astronomía y el Liber de animalibus aristotélico. Y en el studium de Murcia parece haber residido asimismo Raimundo Martí, al que se considera autor, ca. 1275, de un pionero glosario latín-árabe vulgar, el Vocabulista in arabico. Y en Murcia residió muchos años el italiano Giacomo Giunta (Jacobo de la Junta), famoso jurista, redactor de parte de las Siete Partidas alfonsinas y traductor del latín al castellano de dos obras de Derecho... Lo cierto es que en Murcia se llevó a cabo una actividad traductora propia, paralela y contemporánea de la que se llevaba a cabo en la corte. Fue una lástima que ese «florecimiento murciano» no perdurara más allá de la muerte del monarca en 1284 , pero lo cierto es que tras ella Murcia desaparece casi por completo de la historia de la traducción medieval, por lo que hay que pensar que sin duda fue la brevedad de ese «florecimiento» lo que la relegó, creo que injustamente, a un segundo plano.

Anna Gil: Usted califica a Ramón Llull de uno de los más notables traductores del s. XIII. Además del célebre Llibre de la contemplació en Déu, traducido al catalán desde un original árabe desaparecido, ¿qué otras obras tradujo o ayudó a traducir? ¿Qué autores, frades Domingo Marroquino e Rufino Alejandrino, ambos tradutores ao latim de vários tratados de medicina. E o próprio confessor do monarca, frei Pedro Gallego, foi o primeiro bispo de Cartagena, e traduziu ou fez traduzir do árabe ao latim várias obras de medicina, uma Summa de astronomia e o Liber de animalibus de Aristóteles. E parece também ter residido no studium de Múrcia Raimundo Martí, que é considerado autor de um pioneiro glossário latim-árabe vulgar, o Vocabulista in arabico, ca. 1275. E em Múrcia residiu por muitos anos o italiano Giacomo Giunta, famoso jurista, redator das Siete Partidas alfonsinas e tradutor do latim ao castelhano de duas obras de Direito... O certo é que em Múrcia se realizou uma atividade tradutora própria, paralela e contemporânea da que se realizava na corte. Foi uma lástima esse "florecimento murciano" não ter sobrevivido à morte do monarca, em 1284, porém o certo é que depois dela Múrcia desaparece quase por completo da história da tradução medieval, pelo que há de se pensar que, sem dúvida, foi a brevidade desse "florescimento" o que a relegou - creio que injustamente - a um segundo plano.

Anna Gil: O sr. qualifica Ramón Llull de um dos mais admiráveis tradutores do século XIII. Além do célebre Llibre de la contemplació en Déu, traduzido ao catalão de um original árabe desaparecido, que outras obras traduziu ou ajudou a traduzir? Que autores, 
aparte de él, se dedicaron también a la traducción del árabe al catalán en aquel siglo y posteriores?

J. C. Santoyo: Notable por sus muchas traducciones y notable por la versatilidad lingüística que demostró, ya que lo mismo escribía sus obras (la Lógica de Algazel, el Libre del gentil e los tres savis, el Liber de Deo et mundo, el Ars consilii, etc.) en árabe, en catalán o en latín, para después traducirlas él mismo a los otros dos idiomas (caso temprano de doble autotraducción). Algo nada común, desde luego, y no sólo en aquella época, sino en cualquier otra. Anciano ya (parece ser que le fallaba la vista) y residente en Túnez, todavía solicitaba la ayuda de fray Simón de Puigcerdà para traducir al latín más de una docena de tratados que primero había redactado en árabe (primo in arabico) y luego él mismo había traducido al catalán (et postmodum in romancio translatauit). En cuanto a otros traductores del árabe al catalán, en los últimos decenios del s. XIII hallamos a Berenguer Eymeric, Arnau de Vilanova, Benvenist Saporta, Benvenist Avenbenvenist, Mahomat Abenguabarrig y Samuel Abenvives; a finales del XIII y comienzos del XIV, Jahuda Bonsenyor; ya en el s. XIV, Joan Jacme, traductor de un tratado de oftalmología; y Joan de Bònia en el s. XV, traductor en Paterna, al valenciano, de un tratado sobre el sexagenarium, un instrumento de la familia de los ecuatorios. Ello, claro, al margen de numerosos intérpretes árabe-catalán/valenciano. além dele, se dedicaram também à tradução do árabe ao catalão naquele século e nos seguintes?

J. C. Santoyo: Admirável por suas muitas traduções e admirável pela versatilidade linguística que demonstrou, uma vez que ele mesmo escrevia suas obras (a Lógica de Algazel, o Libre del gentil e los tres savis, o Liber de Deo et mundo, o Ars consilii, etc.) em árabe, catalão ou latim, para depois traduzi-las aos outros dois idiomas (caso precoce de dupla autotradução). Algo nada comum, por certo, e não somente naquela época, mas em qualquer outra. Já ancião (parece que a vista lhe falhava) e residindo em Túnis, sempre solicitava ajuda a frei Simón de Puigcerdà para traduzir ao latim mais de uma dúzia de tratados que redatara primeiramente em árabe (primo in arabico) e depois ele mesmo traduzira ao catalão (et postmodum in romancio translatauit). Quanto a outros tradutores do árabe ao catalão, nas últimas décadas do século XIII encontramos Berenguer Eymeric, Arnau de Vilanova, Benvenist Saporta, Benvenist Avenbenvenist, Mahomat Abenguabarrig e Samuel Abenvives; a finais do XIII e início do XIV, Jahuda Bonsenyor; já no século XIV, Joan Jacme, tradutor de um tratado de oftalmologia; e em Paterna, no século $\mathrm{XV}$, Joan de Bònia, tradutor, ao valenciano, de um tratado sobre o sexagenarium (um instrumento de cálculo universal, astronómico e aritmético). Isso, claro, à margem de numerosos intérpretes arábico-catalão/valenciano. 


\begin{abstract}
Anna Gil: En su libro dice, en una ocasión, que «el texto traducido es un texto difundido» y que sobre tal difusión «los poderes públicos o religiosos siempre han querido tener control». Sorprende constatar que incluso en un período tan temprano como el medieval el control sobre la producción y difusión escrita estuviera ya presente. ¿Podría citarnos algunos ejemplos?
\end{abstract}

J. C. Santoyo: En el libro cito ya un buen número de ellos de los ss. XIII, XIV y XV, ejemplos peninsulares y europeos en general: en 1210 el sínodo de París prohibió los escritos de Aristóteles (en su traducción latina, evidentemente); en 1233 Jaime I de Aragón prohibió la posesión de libros religiosos «in romancio»; en Valencia, en 1447, ardieron en la hoguera veinte biblias «falses», sin duda por estar traducidas; como también a finales de ese siglo se hizo desaparecer, casi de raíz, la traducción de la biblia al valenciano hecha por Bonifaci Ferrer \& al.; son sólo algunos ejemplos, porque los citados no son los únicos casos que se dieron a lo largo de la Edad Media, ni en la Península ni en el resto de Europa. Sirva de nuevo ejemplo la orden del rey Afonso $\mathrm{V}$ de Portugal, de 18 de agosto de 1451 , en la que manda quemar los libros de John Wycliff, Jan Hus, Pierre Valdo «y otros»: «Por quanto... son trasladados alguns libros de Joanne Velif e de Ioane Hus e de frei Gaudio e doutros alguns que... son reprobados por falsos e heréticos, que os ditos libros fossem quemados e non fossem mais achados
Anna Gil: Em seu livro diz, em uma ocasião, que "o texto traduzido é um texto difundido" e que sobre tal difusão "os poderes públicos ou religiosos sempre quiseram ter controle". Surpreende constatar que inclusive num período tão inicial como o medieval o controle sobre a produção e a difusão escrita já estava presente. Poderia dar-nos alguns exemplos?

J. C. Santoyo: No livro eu dou já um bom número deles dos séculos XIII, XIV e XV, exemplos peninsulares e europeus em geral: em 1210, o sínodo de Paris proibiu os escritos de Aristóteles (em sua tradução latina, evidentemente); em 1233, Jaime I de Aragão proibiu a posse de livros religiosos "em romance"; em 1447, em Valência, 20 bíblias "falsas" arderam na fogueira, sem dúvida por estarem traduzidas; também a finais desse século fez-se desaparecer, quase completamente, a tradução da bíblia ao valenciano feita por Bonifaci Ferrer et al.; são apenas alguns exemplos, porque os citados não são os únicos casos que se deram ao longo da Idade Média, nem na Península nem no resto da Europa. Sirva novamente de exemplo a ordem do rei Afonso $\mathrm{V}$ de Portugal, de 18 de agosto de 1451, na qual manda queimar os livros de John Wycliff, Jan Hus, Pierre Valdo "e outros": "Por quanto... som trasladados alguns livros de Joanne Velif e de Ioane Hus e de frei Gaudio e doutros alguns que... som reprovados por falsos e heréticos, que os ditos livros fossem queimados e nom fossem mais achados em os nossos 
em os nossos reinos...» $\mathrm{Y}$ todo ello sin contar la autocensura, de la que también hay ejemplos. Recuérdese la versión al francés de la Historia de Alejandro el Grande, de Quinto Curcio, en la que el traductor, Vasco Fernandes de Lucena, censuró los pasajes de homosexualidad convirtiendo al joven Nicómaco en la joven Bagoie, «pour eviter mauvais exemples».

Anna Gil: Hablemos ahora del s. XIV y del escaso interés que ha suscitado entre los especialistas la actividad traductora española, sobre todo si lo contrastamos con los siglos anteriores y con el siglo siguiente. Coincido con usted en que «uno acaba pensando que, al término de la mal llamada Escuela de Traductores de Toledo, se produjo en la Península un gran vacío traductor, del que no se comenzó a salir hasta bien entrado el s. XV, en vísperas y por influencia directa del movimiento renacentista que se vivía en Italia». Usted asegura que nada de ello indica que fuera así. ¿Por qué?

J. C. Santoyo: Porque considero que el s. XIV es un período clave en la historia de la traducción en la Península Ibérica: «clave», porque a lo largo de ese siglo todo cambió. Rara vez, si alguna, ha experimentado la historia de la traducción cambios tan radicales y decisivos como los vividos a lo largo de ese siglo. Téngase en cuenta, en brevísimo resumen y recapitulación, que durante reinos..." E tudo isso sem contar a autocensura, da qual também há exemplos. Recorde-se a versão ao francês da História de Alexandre Magno, de Quinto Curcio, na qual o tradutor, Vasco Fernandes de Lucena, censurou as passagens de homossexualidade transformando o jovem Bagoas ${ }^{3}$ na jovem Bagoie, "para evitar maus exemplos".

Anna Gil: Falemos agora do século XIV e do escasso interesse que a atividade tradutora espanhola suscitou entre os especialistas, sobretudo se o contrastamos com os séculos anteriores e com o século seguinte. Concordo com o sr. em que "acaba-se pensando que, ao término da mal denominada $E s$ cola de Tradutores de Toledo, produziu-se na Península um grande vazio tradutor, do qual não se começou a sair até bem avançado o século $\mathrm{XV}$, em vésperas e por influência direta do movimento renascentista que se vivia na Itália". $O$ sr. afirma que nada disso indica que tenha sido assim. Por quê?

J. C. Santoyo: Porque considero que o século XIV é um período chave na história da tradução na Península Ibérica: "chave" porque ao longo desse século tudo mudou. Raras vezes, se as houve, a história da tradução experimentou mudanças tão radicais e decisivas como as vividas ao longo desse século. Leve-se em conta, num brevíssimo resumo e recapitulação, que durante

\footnotetext{
${ }^{3}$ Parece haver um equívoco no texto original: chamava-se Bagoas, e não Nicômaco, o eunuco que servia (obsequio corporis, com a submissão de seu corpo) Alexandre Magno.
} 
ese siglo prácticamente desaparece el árabe como lengua origen de las traducciones, progresivamente sustituido por el latín, el griego y las lenguas romances intra- $y$ extrapeninsulares (prueba del profundo cambio de intereses que entonces se experimentó); que, en consecuencia, desaparece también la figura intermediaria, frecuente en siglos anteriores, del colaborador judío o mozárabe; que el «centro» traductor se desplaza durante este siglo desde el reino de Castilla al de Aragón; que se traduce ya abundantísimamente, sobre todo en Cataluña, que con harta frecuencia actúa de puente cultural para el resto de la Península; que esa creciente actividad traductora no se limita ya a una corte ni depende del patronazgo real, sino que aparece descentralizada y dispersa por toda la geografía peninsular; que por esa misma dispersión la traducción se consolida en todas las lenguas romances (catalán, castellano, gallego-portugués y aragonés) como vehículo habitual de difusión cultural; que a través del aragonés se inician las traducciones del griego; que asimismo se inician las traducciones desde otras lenguas romances extrapeninsulares: francés, italiano y provenzal; que a su vez dan comienzo las traducciones intrapeninsulares; que al término de este período surgen las primeras reflexiones y críticas traductoras; $y$ que con ellas comienza también a desarrollarse un primer metalenguaje traductor. ¿Hay quien dé más? El contraste con los dos siglos anteriores no puede ser mayor, ni el corte más profundo. esse século praticamente desaparece o árabe como língua origem das traduções, substituído progressivamente pelo latim, pelo grego e pelas línguas romances intra- e extrapeninsulares (prova da profunda mudança de interesses que se experimentou); que, como consequência, desaparece também a figura intermediária, frequente nos séculos anteriores, do colaborador judeu ou moçárabe, que o "centro" tradutor se desloca, durante este século, do reino de Castilha para o de Aragão; que já se traduz muitíssimo, sobretudo na Catalunha, que, com grande frequência, atua como ponto cultural para o restante da Península; que essa crescente atividade tradutora não se limita mais a uma corte nem depende do patronato real, mas que aparece descentralizada e dispersa por toda a geografia peninsular; que, por essa mesma dispersão, a tradução se consolida em todas as línguas romances (catalão, castelhano, galego-português e aragonês) como veículo habitual de difusão cultural; que, através do aragonês, se iniciam as traduções do grego; que se iniciam igualmente as traduções de outras línguas romances extrapeninsulares: francês, italiano e provençal; que, por sua vez, começam as traduções intrapeninsulares; que, ao final deste período, surgem as primeiras reflexões e críticas tradutoras; e que, com elas, começa também a desenvolver-se uma primeira metalinguagem tradutora. Mais que isso? O contraste com os dois séculos anteriores não pode ser maior, nem o corte mais profundo. 
Anna Gil: Usted afirma, apoyándose en García Yebra y otros, que la mayoría de los escritores del s. $X V$ son a la vez traductores. También que el s. XV peninsular es «un mar de traducciones». ¿Cuáles fueron las lenguas más traducidas y a las que más se tradujo durante ese s. XV? ¿Qué traductores destacaron en aquel siglo?

J. C. Santoyo: De modo más o menos extenso, en el libro se traen a colación más de ciento cincuenta traductores del s. XV y más de trescientas cincuenta traducciones llevadas a cabo a lo largo de esa centuria: no es corto número, y creo que desde luego iguala, si no supera, al de autores y textos originales. Sin la menor duda, la lengua más traducida fue el latín, seguida, aunque de lejos, por el italiano y el francés; pero también constan traducciones del árabe, del hebreo, del catalán (al castellano) y del castellano (al catalán y al portugués). A su vez, las dos grandes lenguas meta del siglo fueron (yo diría que a partes aproximadamente iguales) el castellano $\mathrm{y}$ el catalán/valenciano, $\mathrm{y}$ en menor medida el portugués. Muy escasamente representativas son las traducciones al gallego, anecdóticas las versiones al aragonés e inexistentes al vascuence. En cuanto a los traductores más destacados, sus nombres son bien conocidos en el ámbito de una y otra lengua y cultura: en la catalana/valenciana, entre otros, Guillem de Copons, Andreu Febrer, Ferran Valentí, Francesc Alegre, Joan Roís de Corella y Bonifaci Ferrer; y en la castellana, también entre otros, Enrique de Vi-

\begin{abstract}
Anna Gil: O sr. afirma, apoiandose em García Yebra e outros, que a maioria dos escritores do século XV são também tradutores. $E$ ainda, que o século $X V$ peninsular é "um mar de traduções". Quais foram as línguas mais traduzidas e às quais mais se traduziu durante esse século XV? Que tradutores se destacaram naquele século?
\end{abstract}

J. C. Santoyo: De modo mais ou menos extenso, são citados a propósito no livro mais de 150 tradutores do século XV e mais de 350 traduções realizadas ao longo dessa centúria: não é pequeno o número, e acredito que certamente iguala, se não supera, o de autores e textos originais. Sem a menor dúvida, a língua mais traduzida foi o latim, seguida, ainda que à distância, pelo italiano e pelo francês; mas também constam traduções do árabe, do hebraico, do catalão (ao castelhano) e do castelhano (ao catalão e ao português). Por sua vez, as duas grandes línguas meta do século foram (eu diria que em partes aproximadamente iguais) o castelhano e o catalão/valenciano, e, em menor medida, o português. Muito pouco representativas são as traduções ao galego, anedóticas as versões ao aragonês, e inexistentes ao basco. Quanto aos tradutores mais destacados, seus nomes são bastante conhecidos no âmbito de ambas as línguas e culturas: na catalã/valenciana, entre outros, Guillem de Copons, Andreu Febrer, Ferran Valentí, Francesc Alegre, Joan Roís de Corella y Bonifaci Ferrer; e na castelhana, também entre outros, Enrique de Villena, Moisés Arragel de 
1lena, Moisés Arragel de Guadalajara, Alonso de Cartagena y Alonso de Madrigal (el Tostado), este último sobre todo por sus extensas reflexiones en torno a la traducción, Pedro Díaz de Toledo, Alfonso de Segovia, Alfonso de Palencia...

Anna Gil: Es evidente que una obra de esta magnitud no se escribe en dos días: ¿cuántos años le ha llevado la elaboración de la misma? ¿Qué recuerdos tiene de todo el proceso? $Y$, finalmente, permítame que le haga una pregunta un tanto personal: después de un trabajo tan monumental como éste, ¿piensa tomarse unas vacaciones o tiene otros proyectos entre manos?

J. C. Santoyo: El tiempo: varios años, desde luego; yo diría que al menos desde 1995. No en vano han sido más de 500 los libros y artículos consultados, y ahí está la bibliografía y las citas, página a página, para demostrarlo. Ha sido, necesariamente, un proceso lento en el que, con anterioridad a la publicación del libro, he ido desgranando distintos aspectos del mismo en conferencias y artículos a uno y otro lado del Atlántico, y que luego he reunido, hilvanado y encajado en este único volumen. ¿Recuerdos del proceso? Muchos, como es natural: la sensación de ir viendo crecer el libro, el reto que día a día suponía encontrar este o aquel artículo (porque necesitaba verlo y tenerlo en las manos, no me bastaba con saberlo citado por otros)... Pero quizá haya tres recuerdos que emergen sobre todos los demás: los errores, a veces
Guadalajara, Alonso de Cartagena e Alonso de Madrigal (o Tostado), este último sobretudo por suas extensas reflexões em torno à tradução, Pedro Díaz de Toledo, Alfonso de Segovia, Alfonso de Palencia...

Anna Gil: É evidente que uma obra desta grandeza não se escreve em dois dias: quantos anos foram necessários para a elaboração da mesma? Que lembranças tem de todo o processo? $E$, finalmente, permita-me que lhe faça uma pergunta um tanto pessoal: depois de um trabalho tão monumental como este, pensa em tirar umas férias ou tem outros projetos em mãos?

J. C. Santoyo: O tempo: vários anos, por certo; eu diria que, pelo menos, desde 1995. Não por nada foram mais de 500 os livros e artigos consultados, e lá está a bibliografia e as citações, página por página, para comprovar. Foi necessariamente um processo lento, no qual, anteriormente à publicação do livro, fui desfiando distintos aspectos do mesmo em conferências e artigos de um lado e do outro do Atlântico, e que depois reuni, alinhavei e encaixei neste único volume. Lembranças do processo? Muitas, como é natural: a sensação de ir vendo crescer o livro, o desafio que, dia a dia, supunha encontrar este ou aquele artigo (porque necessitava vê-lo e tê-lo nas mãos, não me bastava sabê-lo citado por outros)... Porém, talvez haja três lembranças que sobressaem a todas as demais: os erros, por vezes con- 
considerables, que iba hallando en trabajos anteriores; los «vacíos» de información con que en ocasiones me encontraba (y pongo de ejemplo la traducción cotidiana y/o documental, no la libresca, o bien la traducción oral o interpretación); y, por último, las notables discrepancias que con frecuencia advertía en la estimación crítica de ciertos textos, como en el caso de las Bucólicas de Virgilio en la versión castellana de Juan del Enzina, valorada por unos como traducción, por otros como imitación, o como adaptación, o como obra original, o incluso como parodia de la obra de Virgilio... ¿Tomarme unas vacaciones? La verdad es que no, porque de momento tengo tres cosas entre manos (soy incapaz de trabajar constantemente en un solo tema): una, ya en puertas de imprenta con el título de La traducción: Textos clásicos y medievales, donde he recogido cerca de 200 reflexiones sobre la traducción de autores árabes - tan desconocidos, Hunayn ibn Ishaq, entre ellos-, latinos, ingleses, franceses, italianos, portugueses, alemanes, etc., desde el 400 a. C. hasta el año 1500 (lo malo va a ser editarlo, porque suman más de 500 páginas); otra, una edición crítica de los textos de Alonso de Madrigal, el Tostado, sobre la traducción, ya casi terminado; y la tercera, una monografía sobre la autotraducción, trabajo todavía en proceso de elaboración. De momento todo ello ya me tiene bastante ocupado. sideráveis, que ia encontrando em trabalhos anteriores; os "vazios" de informação com que me encontrava em ocasiões (e dou como exemplo a tradução cotidiana e/ou documental, não a livresca, ou também a tradução oral ou interpretação); e, por último, as enormes discrepâncias que frequentemente eu percebia na valoração crítica de certos textos, como no caso das Bucólicas, de Virgílio, na versão castelhana de Juan del Enzina, considerada por alguns como tradução, por outros como imitação, ou como adaptação, ou como obra original, ou inclusive como paródia da obra de Virgílio... Tirar férias? $\mathrm{Na}$ verdade, não, porque no momento tenho três coisas nas mãos (sou incapaz de trabalhar continuamente em apenas um tema): uma, já estou a caminho da impressão de uma obra intitulada La traducción: Textos clásicos y medievales, onde reuni cerca de 200 reflexões sobre tradução de autores árabes - tão desconhecidos, e dentre eles Hunayn ibn Ishaq -, latinos, ingleses, franceses, italianos, portugueses, alemães, etc., desde 400 a.C. até o ano 1500 (o ruim será editá-lo, porque perfazem mais de 500 páginas); outra, uma edição crítica dos textos de Alonso de Madrigal, o Tostado, sobre tradução, já quase terminado; e a terceira, uma monografia sobre a autotradução, trabalho ainda em processo de elaboração. No momento, tudo isso já me mantém bastante ocupado. 
Trad. de Mauri Furlan maurizius@gmail.com Universidade Federal de Santa Catarina

Anna Gil Bardají anna.gil.bardaji@uab.cat Universitat Autònoma de Barcelona

Julio César Santoyo dfmjsm@unileon.es Universidad de León

Fonte: Quaderns: Revista de Traducció, 17, 2010, 271-281 